\title{
Power Quality in Distribution Grids
}

\author{
P. Thirusenthil Kumaran, P. Pushpakarthick, G. V. Chidambarathanu, M. Venkatachalam, \\ Xavier Raja Durai, R.Jaiganesh
}

\begin{abstract}
Voltage constrained DSTATCOM-based voltage controller is executed for low voltage appropriation system. To meet grid code, unexpected investment postponing, voltage regulator is designed while a complete arrangement could be wanted to tackle guideline issues. 3 yield voltage closed paths with dynamic damping and 2 bus voltage closed paths are associated with control procedure. Also, two circles are incorporated to the control architecture proposed: the idea of Tracking the Minimum Power Point then recurrence closed path. Results demonstrate the guideline limit, the calculation of tracking point of minimum power direct recurrence steadiness.

Record Terms-Power Quality, FACTS Controllers, power point tracking, compensation of frequency, DSTATCOM
\end{abstract}

Rundown phrases- facts conveying, coverage defensive, adequate-anonymization, accumulating.

\section{INTRODUCTION}

Consumers associated may encounter poor voltage guideline. As indicated by Brazilian lattice code, control organizations have obliged cutoff times (days ranging from 15-90) to reestablish the levels of voltage at the point of connecting the grid termed as Point of Common Coupling (PCC).

Instant required for stable solution to be equipped beyond the specified value. During collapse period, the power organization needs to discount each client in the appropriation framework at the duration that the abnormal voltage regulations persist. By means of projected result, grid [13][14] is restored and PCC voltage is reestablished [7] [8]. When the positive arrangement is executed, the voltage controller can be detached [9][10]. Reduced voltage takes place if PCC is a long way from the fundamental matrix converter [19][20] and the separation with the point of common coupling and the matrix transformer can without much of a stretch be more remote than $100 \mathrm{~m}$. Entrance to matrix potential data is troublesome. Satisfying the necessity includes DSTATCOM-based controller is proposed with shunt association with PCC [11][12]. Shunt association keeps away from power interference while the voltage

Revised Manuscript Received on October 15, 2019.

P. Thirusenthil Kumaran, Assistant Professor, Department of EEE Rajalakshmi Engineering College, Chennai, Tamil Nadu, India. (Email: thirusenthilkumaran@gmail.com)

P. Pushpakarthick, Assistant Professor, Department of EEE, Easwari Engineering College, Chennai, Tamil Nadu,India (Email: pushpakarthick@gmail.com)

G. V. Chidambarathanu, Assistant Professor, Department of EEE, Easwari Engineering College, Chennai, Tamil Nadu,India (Email: g.v.chidambarathanu@gmail.com)

M. Venkatachalam, Assistant Professor, Department of EEE, Easwari Engineering College, Chennai, Tamil Nadu,India (Email: chalam203@gmail.com)

Xavier Raja Durai, Assistant Professor, Department of EEE, Easwari Engineering College, Chennai, Tamil Nadu,India (Email: xavier.raja.durai@gmail.com)

R. Jaiganesh, Assistant Professor, Department of EEE, K.Ramakrishnan College of Technology, Trichy, Tamil Nadu, India. (Email: jaiganesh.ram@gmail.com) controller is introduced or disengaged. [1] The paper describes the closed path for voltage-controlled DSTATCOMs ready to alleviate the impacts of matrix recurrence deviation, incredibly expanding the voltage profile which includes of a $3 \varphi 4$ wired VSI (Voltage Source Inverter) connected with the grid throughout a channel. A new procedure developed to produce reference voltage for an appropriation static compensator and used to construct converters [2]. This projected scheme describes numerous merits contrasted with one of the FACTS controllers termed as DSTATCOM where the orientation voltage is discretionarily considered as 1.0 per unit.

Without using any additional hardware the strategy gives DSTATCOM a highlight while improving its power quality (PQ) enhancement. The work is mainly suited for long distribution lines with problems to comply with voltage level standard. Quick acting static synchronous compensator (STATCOM), innovation utilized for receptive power control in transmission and distribution framework. A solitary stage matrix associated PV framework, creates on buck help converter methodology working in DCM (Discontinuous mode of current). Maximum power point (MPPT) [15] methods are utilized in solar photovoltaic (PV) system in augmenting the PV exhibit acquiesce control by following consistently the greatest power point which relies upon boards temperature and on irradiance conditions[16]. The proposed arrangement provides a considerable improvement in the performance when the result is being matched up with the existing system [3]. This work dealing with displays the working standards of a DSTATCOM is utilized to keep up the voltage of a distribution transport [4]. This three-stage connect inverter circuit is provided by two unbiased braced DC storage capacitors understands the DSTATCOM [5]. Three channel capacitors, one for each stage and others are associated in parallel with the DSTATCOM to wipe out high-recurrence exchanging segments.

\section{IMPLEMENTATION}

\section{BLOCK DIAGRAM:}

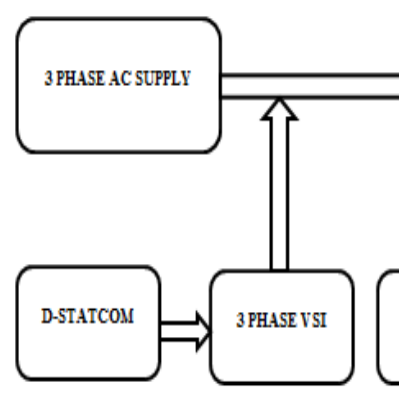

Fig 1: General block diagram

Published By:

Blue Eyes Intelligence Engineering

\& Sciences Publication 


\section{D-STATCOM:}

Distribution Static Compensator (DSTATCOM) planned for improving the dependability and nature of power stream in low voltage distribution grid [17][18]. An IGBT based three-phase inverter circuit with PWIM control strategies provided by a direct current stockpiling storage capacitor associated in parallel with the distribution system realizes DSTATCOM. When the voltage at the inverter end is more than the distribution end, DSTATCOM will act as capacitor. The size of the transport voltage is picked as the ostensible worth for example 1 p.u. The DSTATCOM controller continuously monitors load voltage, load current, capacitor voltage and decides the amplitude and phase degree of the inverter output is distributed to the load and voltage required for power system compensation[6]

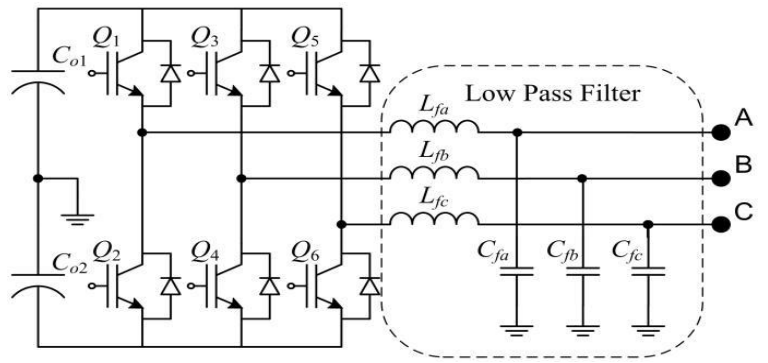

Fig 2: 3 $\varphi$ 4-wire VSI with LC filter.

\section{ACTIVE FILTERS:}

Hybrid active filters (AFs) have been proposed by many researchers. The proposed hybrid AF topologies are essentially an arrangement association of the LC tuned filters and a Three-phase shunt AF. The rating of the shunt Active Filter diminished the fundamental reactive and designated-request harmonic flows are compensated for by the arrangement associated LC tuned filters. A hybrid Shunt Active Filter topology with the hybrid AF has been depicted. The PLCs alongside TCRs control the key reactive power on the source side. As the shunt AF remunerates just for symphonious flows, the necessary rating of the shunt $\mathrm{AF}$ is low and more competent. Similar structure with shunt active filters and connection transformer, Passive filters without inductors can't acquire a high $\mathrm{Q}$ (low damping), yet with them are frequently huge and costly (at low frequencies), may have critical inner obstruction, and may get encompassing electromagnetic sign. The Quality factor and tuned recurrence can be set effectively by shifting resistors. Variable inductances for low recurrence filters are not viable. The enhancer can be utilized to cushion the channel from the electronic segments to fed from variations in which shape of the frequency response gets affects.

\section{CONTROL APPROACH}

The control technique plans to combine three adjusted voltage and furthermore direct the dc bus capacitors. Along these lines, control technique includes 3 yield closed paths, aggregate and differential dc voltage closed path. Previously mentioned approaches structured with the parameter and assessed for a scope of the impedance (0.1 to 10 of $\mathrm{Rg} \&$ $\mathrm{Lg}$ ) through recurrence reaction where it works appropriately. Furthermore, it incorporates closed paths: path liable to voltage adequacy. The contributions of the yield voltage closed path are 3 voltage references made out of bus controller, MPPT and recurrence path. To accomplish sufficient blend, path have to be more powerful. Voltage path has dynamic damp controller to improve soundness of the controller. DSTATCOM activity causes control misfortunes in the influence converter because of semiconductor exchanging. The misfortunes reduce the absolute DC voltage $\left(\mathrm{v}_{0}\right)$. Removal point decides dynamic stream. Consequently, absolute path looks at $\mathrm{v}_{0}$ to the reference $\mathrm{v}_{0} *$ and, through a PI in addition to post controller, set an appropriate $\theta$ to empty dynamic power out of the matrix and restore the power stability between the outline of heaps \& DSTATCOM. DSTATCOM is made out by 3 stage 4-wire VSI and voltage stability of the split capacitors is required. The qualification including split capacitor voltages (vd) is diverged from the reference $\left(\mathrm{vd}^{*}\right)$ and PI notwithstanding post adds to the position generator with a little segment. This segment charges more number of capacitors and hence voltage equality accomplished.

\section{SIMULATION DIAGRAMS AND OUTPUT}

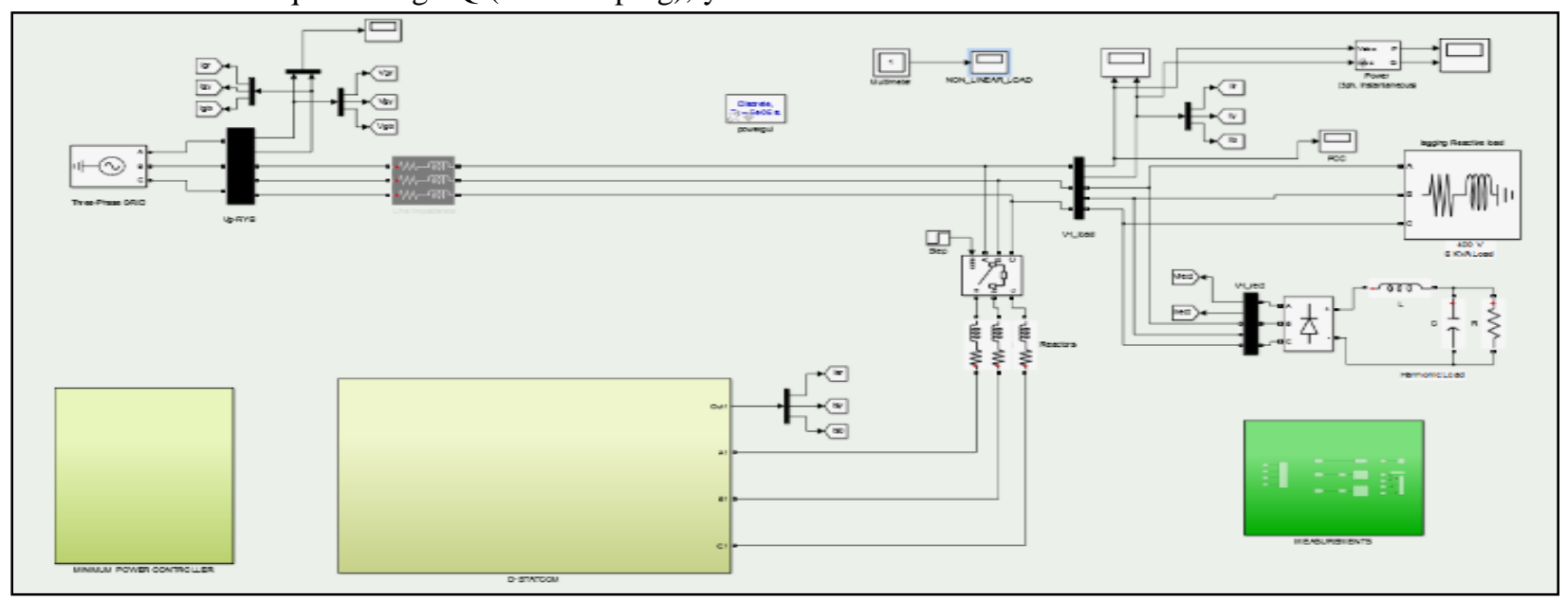

Fig 5.1: Overall Simulation Diagram 


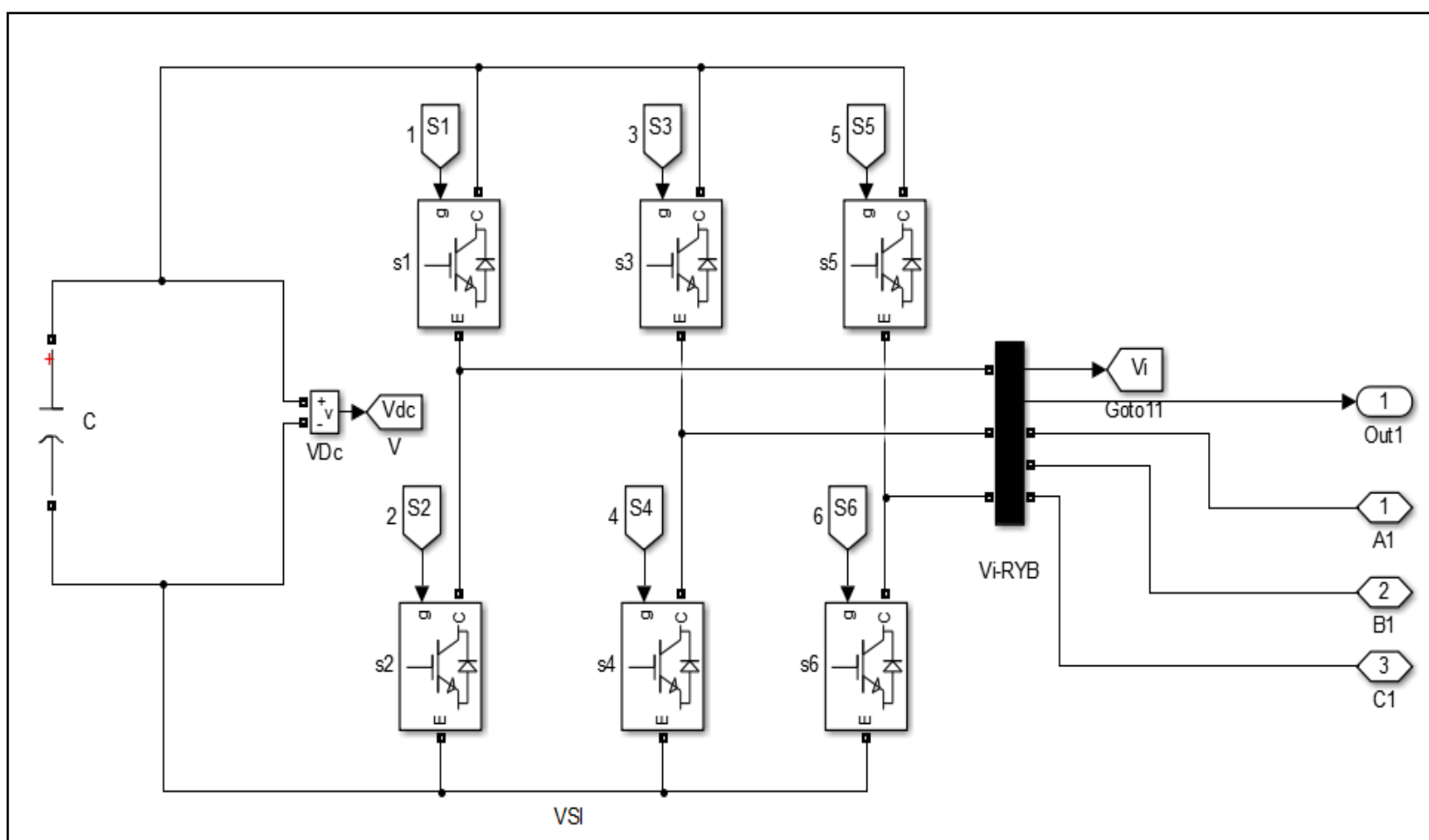

OUTPUT VOLTAGE \& CURRENT WAVEFORM:

\section{SIMULATION RESULTS}

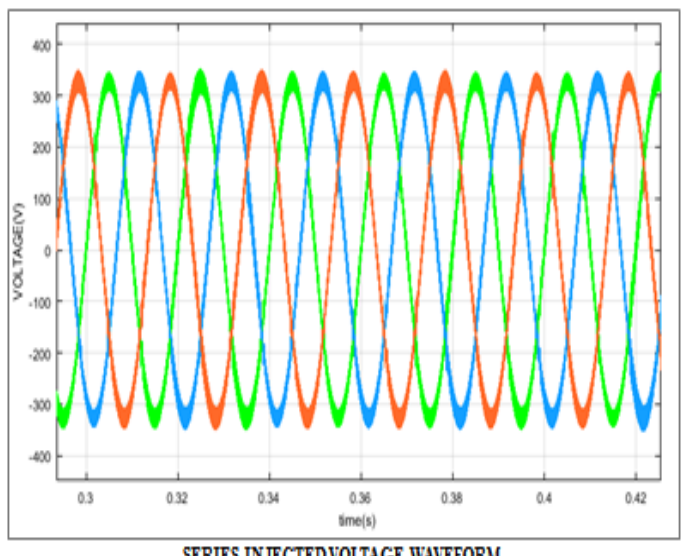

SERIES INJECTED VOLTAGE WAVEFORM

\section{POINT OF COMMON COUPLING PARAMERTERS}

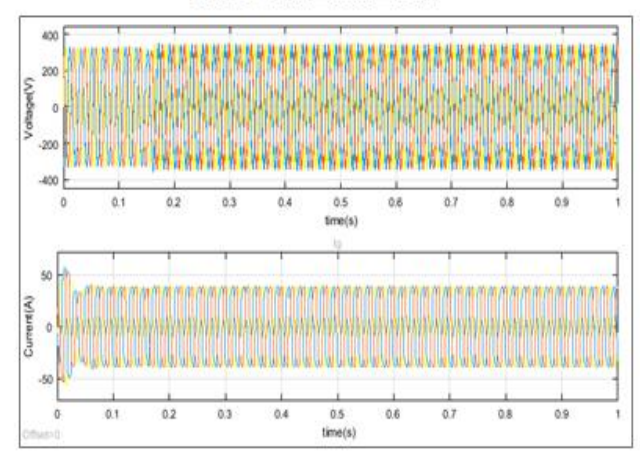

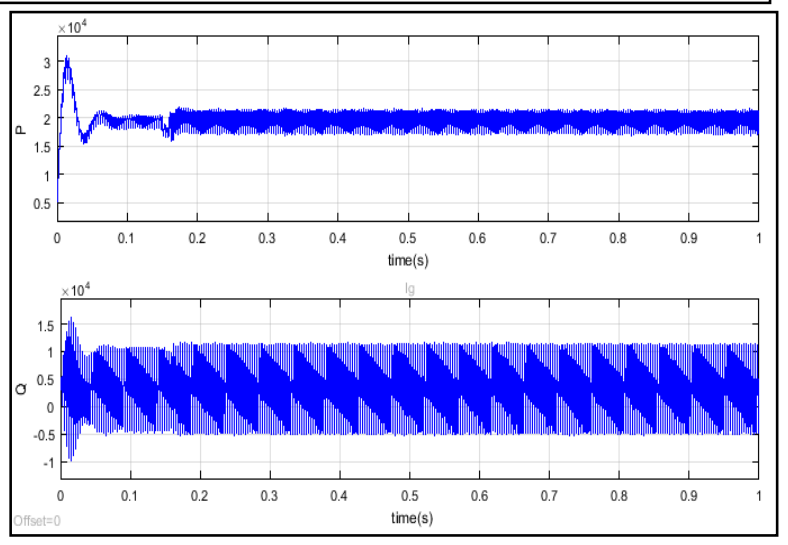

DC LOAD VOLTAGES:

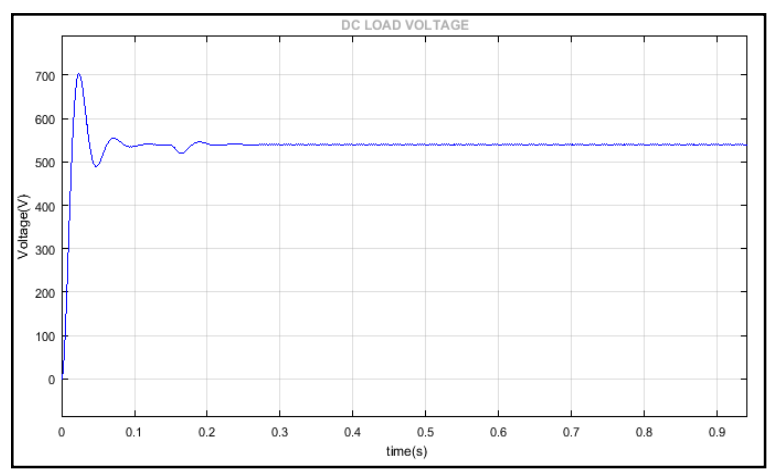

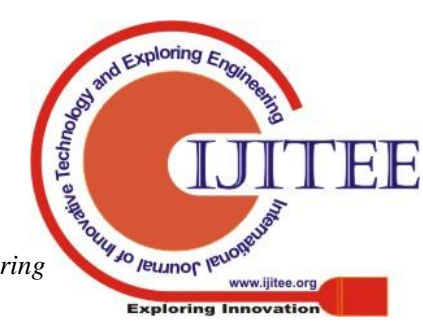




\section{CONCLUSION}

This paper therefore displays a novel idea of utilize a STATCOM on a $24 / 7$ basis, for sustaining the grid as required. Such applications need the approval of grid code and suitable agreement amongst the various users, the inverter manufacturer, internally connecting service provider and framework operator. This D-STATCOM utility intend to open for a conceivable income making open door for the similar framework bolster function at crucial occasions as STATCOM for a application considered.

\section{REFERENCES}

1. M. Mishra, A. Ghosh and A. Joshi, "Operation of a DSTATCOM in voltage control mode," IEEE Trans. Power Del., vol. 18, no. 1, pp. 258-264, Jan. 2003.

2. A. Nazar Ali. "Performance Analysis of Switched Capacitor Multilevel DC/AC Inverter using Solar PV Cells." International Journal for Modern Trends in Science and Technology vol 3,104-109,2017

3. A.T.SankaraSubramanian,P.Sabarish and A.Nazar Ali” A Power factor correction based canonical switching cell converter for VSI fed BLDC motor by using voltage follower technique"IEEE xplore Digital Library,,1$8,2017$.

4. A.NazarAli, D.Sivamani, R.Jaiganesh, Pradeep" Solar powered air conditioner using BLDC motor" IOP Conference Series: Material and Science Engineering,Vol.63,2019

5. P. Thirusenthil Kumaran and C.Kamalakannan, "Real Time Voltage Control using Genetic Algorithm", International Journal of Innovative Research in Advanced Engineering, Vol. 1, No. 12, pp. 31-38, 2014

6. V.Venkatesh,A.NazarAli,R.Jaiganesh,V.Indragandhi”" Extraction and conversion of exhaust heat from automobile engine in to electrical energy" IOP Conference Series: Material and Science Engineering,Vol.63,2019

7. Albert Alexander S and Brad Lehman (2018), "An Intelligent Based Fault Tolerant System for Solar Fed Cascaded Multilevel Inverters", IEEE Transactions on Energy Conversion, Vol.33, No.3, pp.1047-1057, September 2018

8. P.Thirusenthil Kumaran and C.Kamalakannan, "Applying Genetic Algorithm to Minimize Power Loss and Establish Voltage Control", International Journal of Latest Trends in Engineering and Technology, Vol. 6, No. 1, pp. 268-277, 2015.

9. P. Thirusenthil Kumaran and C.Kamalakannan, "Real Power Loss Minimization and Voltage Control using Genetic Algorithm" International Journal of Applied Engineering Research, Vol. 10, No. 6, pp. 5183-5188, 2015.

10. Albert Alexander S \& Manigandan T, (2009), "Digital Switching Scheme for Cascaded Multilevel inverters", Proceedings of the Third International Conference on Power Systems, Indian Institute of Technology, Kharagpur, 27-29 December 2009.

11. A.Nazar Ali, R. Jayabharath, and M. D. Udayakumar" An ANFIS Based Advanced MPPT Control of a WindSolar Hybrid Power Generation System" International Review on Modelling and Simulations (IREMOS)" Vol. 7.4, No. 10, pp. 638-643, 2014

12. Ali, A. Nazar, R. Jeyabharath, and M. D. Udayakumar. "Cascaded Multilevel Inverters for Reduce Harmonic Distortions in Solar PV Applications." Asian Journal of Research in Social Sciences and Humanities ,Vol $6.11,2016$
13. P. Thirusenthil Kumaran and C.Kamalakannan, "Cost Optimisation and Voltage Control of Power System using Genetic Algorithm", Journal of Computational and Theoretical Nanoscience, Vol. 14, No. 4, pp. 1-5, 2017.

14. P. Thirusenthil Kumaran and C.Kamalakannan, "Voltage and Reactive Power Control of Power Systems using Intelligent Control Techniques", World Applied Sciences Journal, Vol. 35, No. 4, pp. 541-547, 2017.

15. Albert Alexander S, (2017), "Development of High Performance Solar Photovoltaic Inverter with Advanced Modulation Techniques to Improve Power Quality", International Journal of Electronics (Taylor and Francis), Vol.104, Issue 2, pp.174-189.

16. P. Thirusenthil Kumaran and C.Kamalakannan, "Negative Extinction angle Method and Hysterisis Controller Method for Power System Applications", International Journal of Science and Innovative Engineering \& Technology, Vol. 1, No. 1, pp. 221-226, 2017.

17. L.Nagarajan, A. Nazar Ali and A.Arunkumar," Islanding Detection Technique for Grid connected AC Distribution System" i-manager's Journal on Future Engineering and Technology, Vol. 13, No. 1, pp. 221-226, 2018

18. A.Nazar Ali, R. Jayabharath, and M. D. Udayakumar" A Single phase high efficient transformer less inverter for PV grid connected power system using ISPWM Techniques", International journal of applied engineering research, , Vol. 10, No. 10, pp.7489, 2015

19. A. Nazar Ali, N. Gowri, and P. G. Scholor. "Power factor correction based bridgeless single switch SEPIC converter fed BLDC motor." Advances in Natural and Applied Sciences Vol.10.3, 190-198, 2016.

20. Prarthiv Evan Poudyal, V Vigneshwar, N K Kumar,V Indragandhi, A.Nazar Ali" Design and simulation of Phase shifted DC-DC full bridge converter'IOP: Conference Series: Material and Science Engineering, Vol.63, 2019 